\title{
Chemical effects in ion mixing of a ternary system (metal-SiO $\mathrm{O}_{2}$ )
}

\author{
T. Banwell and M-A. Nicolet \\ California Institute of Technology. Pasadena. California 91125 \\ T. Sands \\ Biell Communications Research, Inc., Red Bunk, New Jersey $07701-7020$ \\ P. J. Grunthaner \\ Jet Propulsion Laboratory, Pasadena, California 91109
}

(Received 31 July 1986; accepted for publication 12 January 1987)

\begin{abstract}
The mixing of $\mathrm{Ti}, \mathrm{Cr}$, and $\mathrm{Ni}$ thin fims with $\mathrm{SiO}_{2}$ by low-temperature $\left(-196-25^{\circ} \mathrm{C}\right.$ ) irradiation with $290 \mathrm{keV} \mathrm{Xe}$ has been investigated. Comparison of the morphology of the intermixed region and the dose dependences of net metal transport into $\mathrm{SiO}_{2}$ reveals that long range motion and phase formation probably occur as separate and sequential processes. Kinetic limitations suppress chemical efiects in these systems during the initial transport process. Chemical interactions infuence the subsequent phase formation.
\end{abstract}

A number of mechanisms are known to contribute to atomic transport in ion mixing. ${ }^{1-4}$ Recoil implantation from single high-energy collisions can be recognized from its linear fluence dependence. ${ }^{2}$ A very large number of target atoms experience short range displacements induced by the cascace of higher generation collisions. The motion within a cascade is predominately isctropic, although the anisotropic fux of secondary recoils may also be significant. Electronic interactions introduce chemical effects after the average particle energy has diminished to about $1 \mathrm{eV} .{ }^{3}$ Several recent studies have characterized the correlation between the extent of ion-irradiation-induced mixing and thermochemical properties for binary metal-metal systems. ${ }^{3-5}$ Much of tho mixing in metal-metal systems apparentiy occurs in this thermalized regime. ${ }^{6}$ Chemical effects can bias the random walk motion within this regime and produce a Darken effect. Johnson et al. have proposed for these systems that the metallurgical phases are formed after the modified concentration profile is established. ${ }^{3}$ Rapid quenching imposes kinetic constraints which may favor formation of metastable phases.

This letter summarizes results from our studies of ion mixing in $\mathrm{Ti} / \mathrm{SiO}_{2}, \mathrm{Cr} / \mathrm{SiO}_{2}$, and $\mathrm{Ni} / \mathrm{SiO}_{2}$ bilayers induced by $290 \mathrm{keV} \mathrm{Xe}$ irradiation at $25^{\circ} \mathrm{C}$ and $-196^{\circ} \mathrm{C}$. Thermodynamically, these three systems are quite distinct. There are many favorable reactions of $\mathrm{Ti}$ with $\mathrm{SiO}_{2}{ }^{\text {. Segregated }}$ $\mathrm{TiSi}_{2}$ and $\mathrm{Ti}_{2} \mathrm{O}_{3}$ layers were the observed reaction products for thermal annealing above $670^{\circ} \mathrm{C}$. The case of $\mathrm{Cr}$ is intermediate; a few of the reactions for $\mathrm{Cr}$ forming $\mathrm{Cr}_{2} \mathrm{O}_{3}$ are favorable but kinetically inhibited ${ }^{7,8}$ The reactions of $\mathrm{Ni}$ with $\mathrm{SiO}_{2}$ are all unfavorabie. ${ }^{7}$ We compare here the amount of metal transport into the $\mathrm{SiO}_{2}$ with the morphology of the infermixed region produced by the ion irradiation.

A set of $\mathrm{Ti}, \mathrm{Cr}$, and $\mathrm{Ni}$ samples on $\sim 1 \mu \mathrm{m}$ thermally grown $\mathrm{SiO}_{2}$ was prepared by electron beam evaporation with a range of film thicknesses chosen for each metal. $290 \mathrm{keV}$ Xe irradiations were performed at $-196^{\circ}$ or $25^{\circ} \mathrm{C}$ with a prescribed fluence $\phi$ of $1-15 \times 10^{15} \mathrm{~cm}^{-2}$. The projected range of Xe in these metals is $34 \mu \mathrm{g} / \mathrm{cm}^{2}$ with $11.5 \mu \mathrm{g} / \mathrm{cm}^{2}$ standard deviation. ${ }^{9}$ The unreacted metal was selectively re- moved after the irradiation by chemical etching, as reported previously. ${ }^{8,10,11}$ The distribution of metal in the $\mathrm{SiO}_{2}$ was measured using $2 \mathrm{MeV} \mathrm{He}$ Rutherford backscattering spectrometry (RBS) with a 1-10 $\mathrm{mm}^{2}$ beam spot. High-resolution cross-sectional transmission electron microscopy (TEM) was used to determine the structure and morphology of the intermixed region. The TEM samples were cleaved and epoxied face to face prior to thinning. X-ray photoelectron spectroscopy (XPS) was employed to identify changes in chemical states. High-resolution cross-sectional TEM images of samples irradiated at $25^{\circ} \mathrm{C}$ after removal of the free metal are shown in Fig. 1 for (a) $\mathrm{T}$ and (b) $\mathrm{Cr}$ with

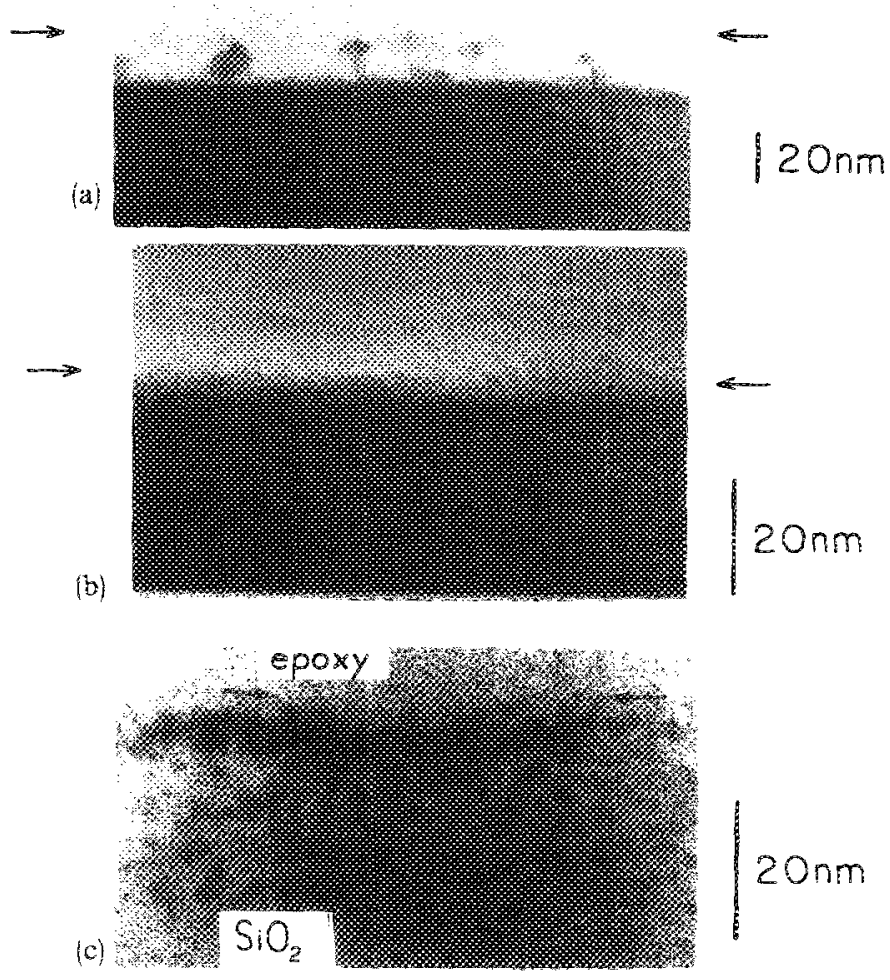

FIG. 1. Kigh-ressintion images of irradiated (a) $\mathrm{Ti}$, (b) $C r$, and (c) $\mathrm{Mi}$ samples after removing free-metal layer. 
$\phi=10 \times 10^{15} \mathrm{Xe} \mathrm{cm}^{-2}$, and (c) Ni with $\phi=6 \times 10^{15} \mathrm{Xe}$ $\mathrm{cm}^{-2}$. The initial metal thickness was $23 \mu \mathrm{g} / \mathrm{cm}^{2}$. Arrows identify the $\mathrm{SiO}_{2}$ interface. The dark clusters in (c) correspond to a $\mathrm{Ni}$ phase. Most of the apparent $\mathrm{Ni}$ is located within a 5-nm region centered $5 \mathrm{~nm}$ below the $\mathrm{SiO}_{2}$ interface. This $\mathrm{Ni}$ is contained in crystalline clusters which show a lattice spacing of $0.241 \pm 0.004 \mathrm{~nm}$ in high-resciution imaging. A single Ni $2 p_{3 / 2}$ line was observed at $853.6 \mathrm{eV}$ binding energy using XPS. These results imply that cubic NiO is the only Ni phase present. The Cr samples show no evidence of crystalline phase formation or clustering. TEM would probably reveal crystaline phases if they were present. TEM is not sensitive, however, to the $\mathrm{Cr}$ distribution if it is disordered since the electron scattering factor for $\mathrm{Cr}$ is not significantly different from that for Si. The Ti sample in Fig. I(a) exhibits considerable structure. There are crystalline ciusters at the interface which show a lattice spacing of $0.33 \pm 0.01 \mathrm{~nm}$. This value corresponds to a strong reflection in several titanium oxides, although it is also possible that they are TiSi ${ }_{2}$. The Ti $2 p_{3 / 2}$ peak was identified with a $459-\mathrm{eV}$ binding energy, also suggesting oxide formation. There is, in addition, a band of amorphous or partially crystalline material centered at a depth of $10 \mathrm{~nm}$, well beyond the electron escape depth, which probably contains Ti. These results clearly demonstrate that the detailed morphoiogy of the intermixed region is strongly affected by the chemistry of the system.

A different perspective is given by Fig. 2 which shows the RBS average metai concentration $[M]$ plotted logarithmically versus depth $x$ into the $\mathrm{SiO}_{2}$ for $\phi=10 \times 10^{15} \mathrm{Xe}$ $\mathrm{cm}^{-2}$ at $25^{\circ} \mathrm{C}$. Recall that the depth profile inferred from a RBS spectrum is an average over the area of the sample exposed to the He beam of the actual distribution of atoms in the sample at a depth corresponding to a given energy loss. The profiles in Fig. 2 consist of two distinct parts. Most of the metal is contained in a resolution-limited peak near the interface. In contrast to the Ni bearing region, which clearly lies below the interface, the average distribution of $\mathrm{Ti}$ and $\mathrm{Cr}$ may extend to the surface monotonically. In each case, a significant discontinuity in the metal distribution is maintained across the metal-SiO $\mathrm{S}_{2}$ interface which is not expected for regular diffusion. The tails extending beyond $\sim 40 \mathrm{~nm}$ result from recoil implantation. ${ }^{8,11}$ Both the peak and the tail were seen in the RBS spectra for all of the irradiated samples, although with differing proportions. The RBS profiles of samples irradiated at $-196^{\circ} \mathrm{C}$ were indistinguishable from the $25^{\circ} \mathrm{C}$ samples.

The areal density of $M$ atoms incoroorated in the $\mathrm{SiO}_{2}$, $[M]_{s}(\phi)=\int[M](\phi, x) d x$, can be calculated from the profiles such as shown in Fig. 2 for different doses $\phi$. It is found for each sample configuration that $[M]_{S} \simeq \alpha_{M} \phi^{i}+\omega_{M} \phi^{1 / 2}$. This was deduced from a linear relationship observed between $\phi^{-1 / 2}[M]_{s}$ and $\phi^{1 / 2}$ over the investigated fluence range. The $\phi^{1}$ component arises from anisotropic processes while random walks generated by overlapping cascades introduce a $\phi^{1 / 2}$ dependence. For a given initial film areal density, the $\alpha_{M}$ are similar among $\mathrm{Ti}, \mathrm{Cr}$, and $\mathrm{Ni}$. This is expected if recoil implantation is the dominant anisotropic process since these metals are collisionally similar. The mixing asso-

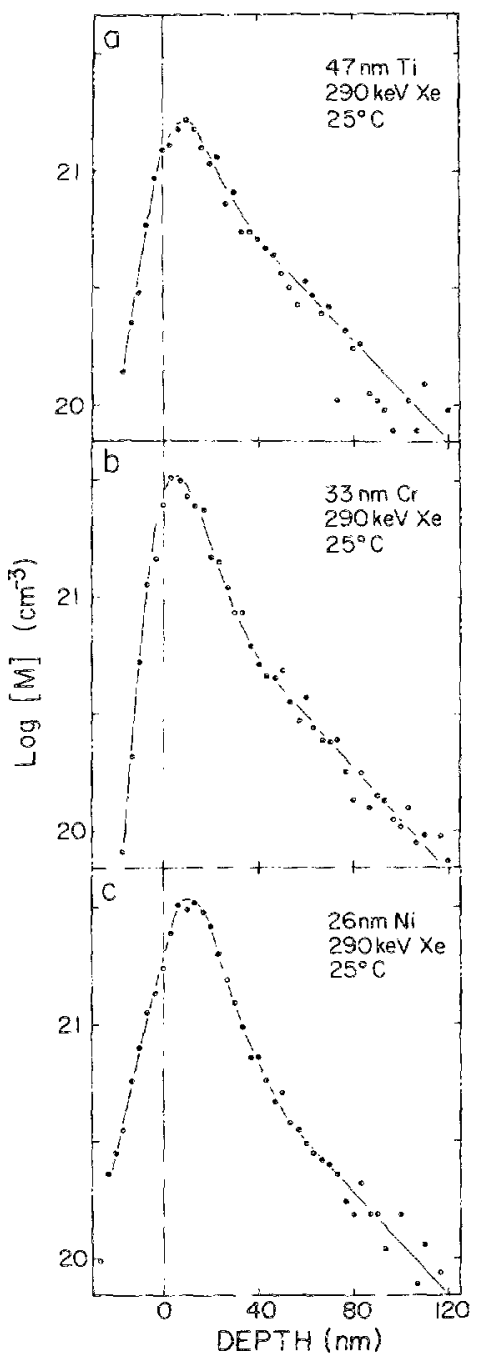

FIG. 2. RBS depth profiles of (a) $\mathrm{Ti}$, (b) $\mathrm{Cr}$, and (c) $\mathrm{Ni}$ in $\mathrm{SiO}_{2}$ produced by $10 \times 10^{15} \mathrm{~cm}^{-2} X e$ irradiation. The free metal was previously removed.

ciated with $\omega_{M}$ correlates linearly with the energy deposited in the metal per incident Xe per unit depth $\left(F_{D}\right)$ at the interface. ${ }^{8}$ There is, however, no grouping of the data points to suggest a chemical trend.

Over the dose range investigated, the number of metal atoms incorporated in the $\mathrm{SiO}_{2}$ follows the same description for all three metals. We conclude from this common behavior that in this dose range the process responsible for the metal incorporation in to the $\mathrm{SiO}_{2}$ is probably the same for all three metals, even though the individual chemistry of these rnetals with $\mathrm{SiO}_{2}$ is different. This contrasts with the mixing behavior of transition metal bilayers, where the ion mixing at low temperatures (i.e., in the absence of radiation enhance. ments) correlates with chemical mixing enthalpies. ${ }^{3,4}$ The different chemical affinities are expressed in the final morphology (Fig. 1), not in the average spatial distribution of the metal in $\mathrm{SiO}_{2}$ (Fig. 2) or its dose dependence. The dominant processes governing mixing in $\mathrm{Ni} / \mathrm{SiO}_{2}$ were tentatively identified by a series of parametric investigations. ${ }^{8}$ For $\phi>\sim 10^{15} \mathrm{~cm}^{-2}$, the concentration of $\mathrm{Nin}$ near the interface is probably determined by the competition between second- 
ary recoil injection of $\mathrm{Ni}$ into the $\mathrm{SiO}_{2}$ and diffusion of $\mathrm{Ni}$ back to the $\mathrm{Ni}-\mathrm{SiO}_{2}$ interface. The injection could have a linear $F_{D}$ dependence. ${ }^{* 12}$

Our observations only partiy concur with other reports. Farlow er al. ${ }^{13}$ find little mixing for $\mathrm{Cr}$ on $\mathrm{SiO}_{2}$ under experimental conditions similar to ours, but report substantial mixing for Ti on $\mathrm{SiO}_{2}$. In contrast, we observe similar mixing for both $\mathrm{Cr}$ and $\mathrm{Ti}$ at room temperature and below. The reasons for this discrepancy are unctear.

Additional discrepancies arise when comparing published results for Cr at elevated temperatures. Farlow et al. ${ }^{13}$ see a decrease in the mixing of $\mathrm{Cr}$ on $\mathrm{SiO}_{2}$, while earlier work reports the opposite. Nickel intermixes less at elevated temperatures than at room temperature, while the converse is true for $\mathrm{Ti} \cdot{ }^{10}$ This is readily understood as an expression of the chemical driving force in the system when kinetic limitations disappear. ${ }^{13}$ In the case of $\mathrm{Cr}$, the chemical driving forces are weak and the outcome may be dominated by second-order effects. This is suggested by the apparent diserepancy in the mixing of $\mathrm{Cr}$ at elevated temperatures.

The results reported here for $T, C r$, and $N$ show that at room temperature kinetic constraints impede the infuence of chemical driving forces. White et al. ${ }^{14}$ show that $N$ b mixes more readily with $\mathrm{SiO}_{2}$ at room temperature than $\mathrm{T}, \mathrm{Cr}$, and $\mathrm{Ni}$ do. In the $\mathrm{Nb}$ case, the kinetic constraints are evidently relaxed. We believe that the kinetic constraints are associated whithe evolution of a cascade. A dense cascade can last long enough to allow for significant chemical interaction.

In summary, it is found that at room temperature and below, the net trarsportation of metal into the $\mathrm{SiO}_{2}$ is similar for $\mathrm{T}, \mathrm{Cr}$, and Ni. For these systems, the amount of intermixing does not correlare with the metal's reactivity. This suggests that there are kinetic limitations asscciated with a high activation energy for the relatively complicated exchange reactions, as occurring in these ternary systems, and the short duration of the cascade. At low remperatures, the metal depth distribution is probably established before chemistry is important. The limitations can be circumvented at elevated irradiation temperatures where the mixing rate shows a positive correlation with reactivity. ${ }^{10}$

This work was fnancialy supported in part by the Office of Naval Research under contract No. Noo014-84-K. 0275 and by the National Science Foundation under grant ko. DMR-8421119. T. Banwell thanks IBM for a fellowship during this work.

'J. W. Mayer, B. Y. Tsaur, S. S. Lau, and L. S. Hung, Nud. Instrum. Methods $182 / 183,1$ (1981).

2P. Sigmund and A. Gras-Marti, Nucl. Instrum. Methods 182/183, 25 (1981).

'W. L. Johnson, $Y_{-}$- R. Cheng, M. Van Rossum, and M-A. Nicolet, Nerel. Instrum. Methods B 7/8,657 (1985).

${ }^{4}$ Y.T. Cheng, M. Wan Rossum, W. L. Johnson, and M-A. Nicoler, Appl. Phys. Lett. 45, 185 (1984).

${ }^{5} F$. D'Heurie, J. E. E. Baglin, and G. J. Clark, J. Appl. Phys. 57, 1426 (1985).

6. M. Paine and R. S. Averback, Nucl. Instrum. Methols B 7/8, 666 (1985).

${ }^{7}$ R. Pretorius, J. M. Harris, and M-A. Nicolet, Solid State Electron. 21, 667 (1978).

${ }^{8}$ T. C. Banwell, Ph.D. Thesis, California Institure of Technology, 1986.

"K. B. Winterbon, Ton Implantation Range and Energy Deposion Distributions (IFI Plenum, New York, 1975).

${ }^{10}$ T. Banwell, B-X. Liu, I. Golecki, and M-A. Nicolet, Nue?. Instrum. Methods 209/210, 125 (1983).

"T. C. Banwell, M-A. Nicolet, P. J. Grunthaner, and T. Sands, in Energy Beam-Solid Interactions and 7ransient Thermal Processing 1984, Mater. Res. Soc. Symp. Proc., edited by D. K. Biegelsen, G. A. Rozgonyi, and C. V. Shank (MRS, Pittsburgh, 1984), Vol. 35, p. 545.

${ }^{12} \mathrm{G}$. Falcone and A. Oliva, Appl. Phys. Lett. 42, 41 (1983).

${ }^{13}$ G. C. Farlow, B. R. Appleton, L. A. Boatner, C. J. McHargue, C. W. White, G. J. Clark, and J. E. E. Baglin, Mater. Res. Soc. Symp. Proc.. edited by D. K. Biegelsen, C. A. Rozgonyi, and C. V. Shank (MRS, Pitsburgh, 1985), Vol. 45, p. 137.

${ }^{14}$ C. W. White, G. C. Farlow, 5. Narayau, G. J. Clark, and J. E. Baglin, Mater. Lett.2, 367 (1984). 